\title{
Supplement to
}

\section{Root uptake under mismatched distributions of water and nutrients in the root zone.}

Jing Yan ${ }^{1}$, Nathaniel A. Bogie ${ }^{2}$, and Teamrat A. Ghezzehei ${ }^{1}$

${ }^{1}$ Life and Environmental Sciences Department, University of California, Merced, CA 95343, USA

${ }^{2}$ Geology Department, San Jose State University, San Jose, CA 95192, USA

\section{Composition of nutrient solution}

Commercial hydroponic nutrient solution (FloraDuo A and B, General Hydroponics, Santa Rosa, CA) derived from Ammonium Nitrate, Calcium Nitrate, Magnesium Nitrate, Magnesium Sulfate, Monopotassium Phosphate, Potassium Nitrate, Potassium Sulfate, Sodium Molybdate was diluted accordingly for nutrient application. A detailed description of chemical composition can be obtained from the company website.

\section{Canopy NDVI and nitrogen content}

NDVI was calculated based on the hyperspectral reflectance of plant leaves harvested on day of 139 to 141 after transplantation using equation 1 .

$\mathrm{NDVI}=\frac{\mathrm{R}_{800}-\mathrm{R}_{670}}{\mathrm{R}_{800}+\mathrm{R}_{670}}$

where $\mathrm{R}_{670}$ and $\mathrm{R}_{800}$, i.e. reflectance intensity at 670 and $800 \mathrm{~nm}$, represent leaf reflectance at red and near-infrared area. NDVI index across the canopy was shown in Figure 2 (a-c).

Plant leaves and stems along the canopy were divided into subsections for nitrogen $(\mathrm{N})$ content analysis (Figure 2 (d-f)). We calculated total $\mathrm{N}$ mass by integrating subsection $\mathrm{N}$ content to their dry masses. We further corrected total $\mathrm{N}$ uptake, i.e. net $\mathrm{N}$ uptake, by subtracting initial $\mathrm{N}$ mass, which was estimated from the following equation:

$\mathrm{N}_{0}=\mathrm{m}_{0} \cdot \mathrm{f} \cdot \mathrm{C}_{\mathrm{N}}$

where $\mathrm{m}_{0}, \mathrm{f}$ and $\mathrm{C}_{\mathrm{N}}$ represent initial fresh mass, final dry mass and $\mathrm{N}$ content of plant tissues.

Mature leaf samples (i.e. single leaflets of the $3^{\text {rd }}$ to $6^{\text {th }}$ leaves from the growing tip) were further selected for NDVI and $\mathrm{N}$ content comparison at the whole-plant scale as suggested by Kalra (1998). We used Welch's ANOVA test Welch (1947) to compare NDVI and N content across treatments. No statistical significance was observed ( $p>0.05$; Table A1). 


\section{Comparison of root distribution}

The distribution of root mass within the top, middle, and bottom $(0-8,8-18,18-26 \mathrm{~cm})$ depth intervals were compared using a two-way ANOVA test and Games-Howell posthoc test for multiple comparisons Games and Howell (1976). The results of mean \pm standard deviation along with significant letters were shown in Table A2.

\section{Soil water retention characteristics}

25 The relationship between measurements of soil water content and water potential were fitted and modeled based on Brooks Corey's water retention function shown below Brooks and Corey $(1966,1964)$ :

$\Theta=\frac{\theta-\theta_{r}}{\theta_{s}-\theta_{r}}$

$\Theta= \begin{cases}\left(\psi / \psi_{b}\right)^{\lambda} & \text { if } \psi \leq \psi_{b} \\ 1 & \text { otherwise }\end{cases}$

where $\Theta$ and $\psi$ are relative water saturation [-] and soil water potential [kPa]); $\psi_{b}$ is soil water potential [kPa] at the air-entry point; $\theta, \theta_{r}$ and $\theta_{s}$ are actual, residual and saturated volumetric water content $[\mathrm{v} / \mathrm{v}]$.

\section{Calculation of the magnitude of hydraulic redistribution}

The HR magnitude is calculated as the difference in soil water storage between the daily minimum of earlier days and daily maximum of subsequent days Meinzer et al. (2004). Specifically, we selected results from day of 54 to 138 after transplantation, when HR consistently occurred (except one sensor starting from day of 60 after transplantation). Five out of the six sensors perform according to specification, and thus results from those sensors were used. The rhizosphere water potential was first converted to water content $[\mathrm{v} / \mathrm{v}]$ using the soil water retention curves mentioned above. We then scaled it to an equivalent soil moisture depth in the $50 \mathrm{~mm}$ soil intervals where maximum root density was observed. After that, we calculated daily water outflow $\left[\mathrm{mm} \mathrm{day}^{-1}\right]$ by subtracting daily minimum water storage from the subsequent daily maximum storage. The time of the HR occurred was assigned to the date of the nighttime, where the maximum water potential was observed. The mean soil water potential in Figure 4 was calculated between noon of previous days and days of HR occurred. 

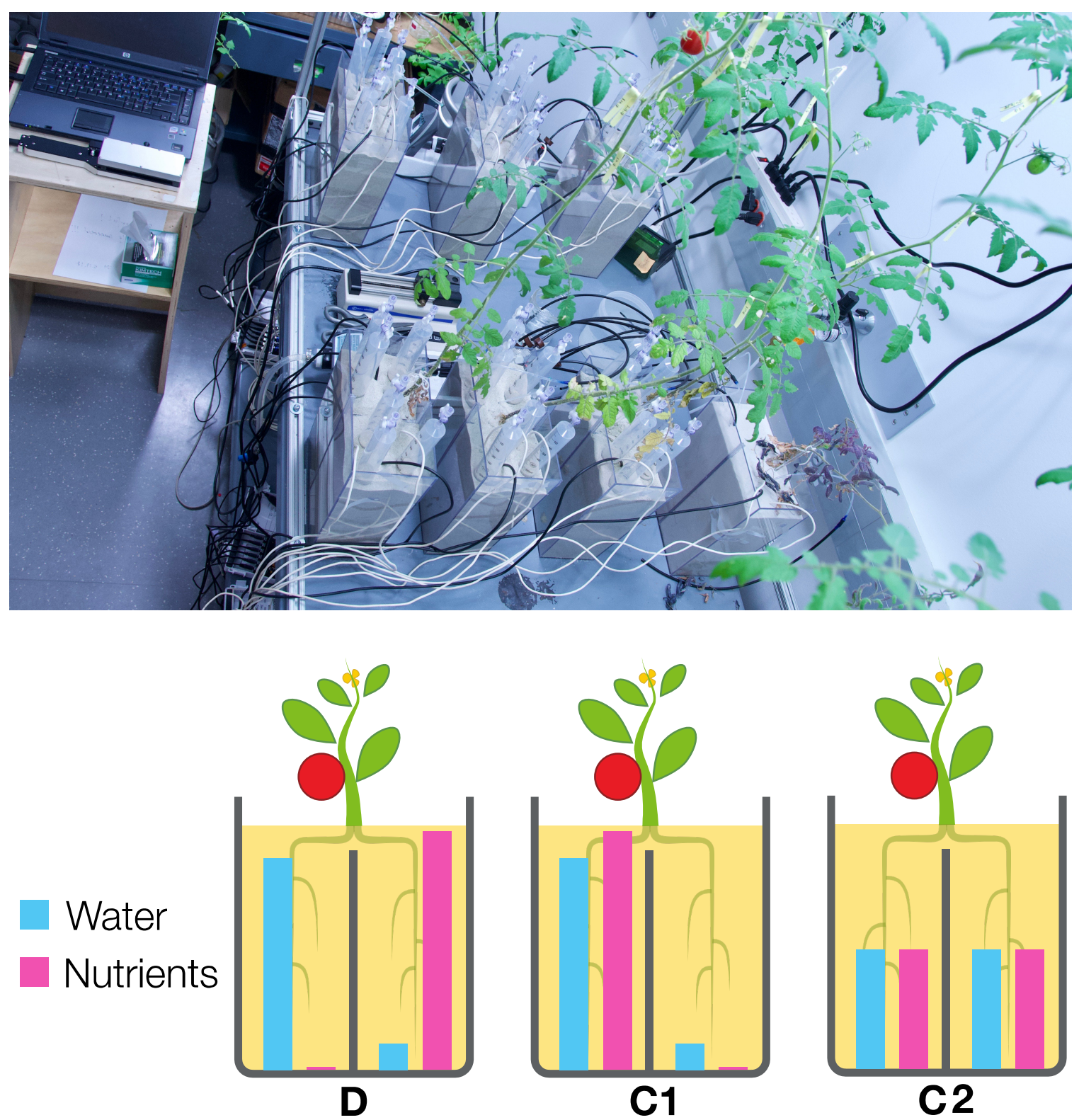

Figure 1. Picture of experimental setup (top) and summary of irrigation pattern across treatments (bottom). The height of the bars indicates the proportion of total water and nutrient application during the five-month growth cycle. 

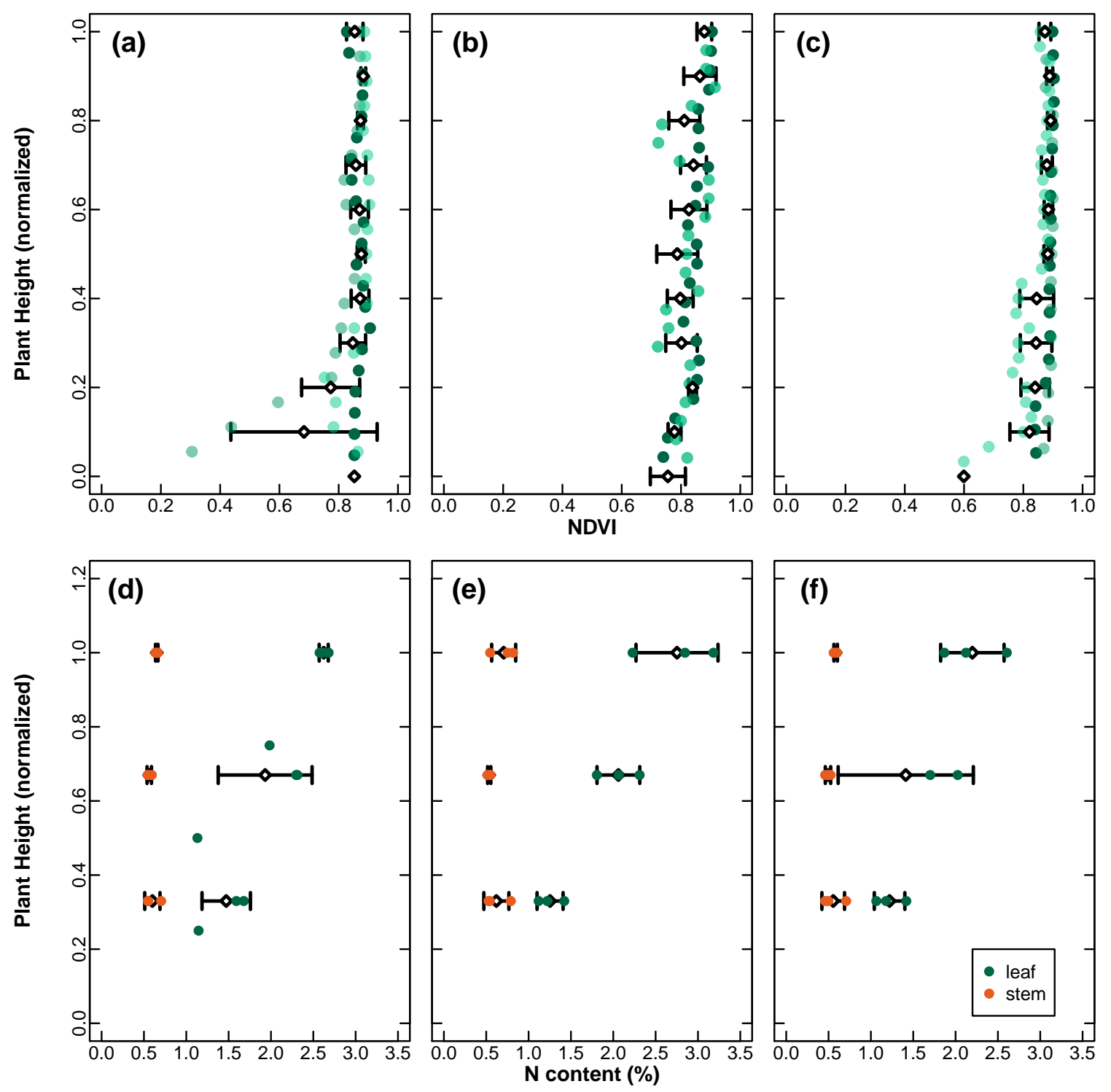

Figure 2. NDVI and nitrogen content of stem and leaf as a function of normalized plant height in treatment D (a, d), C1 (b, e) and C2 (c, f). 

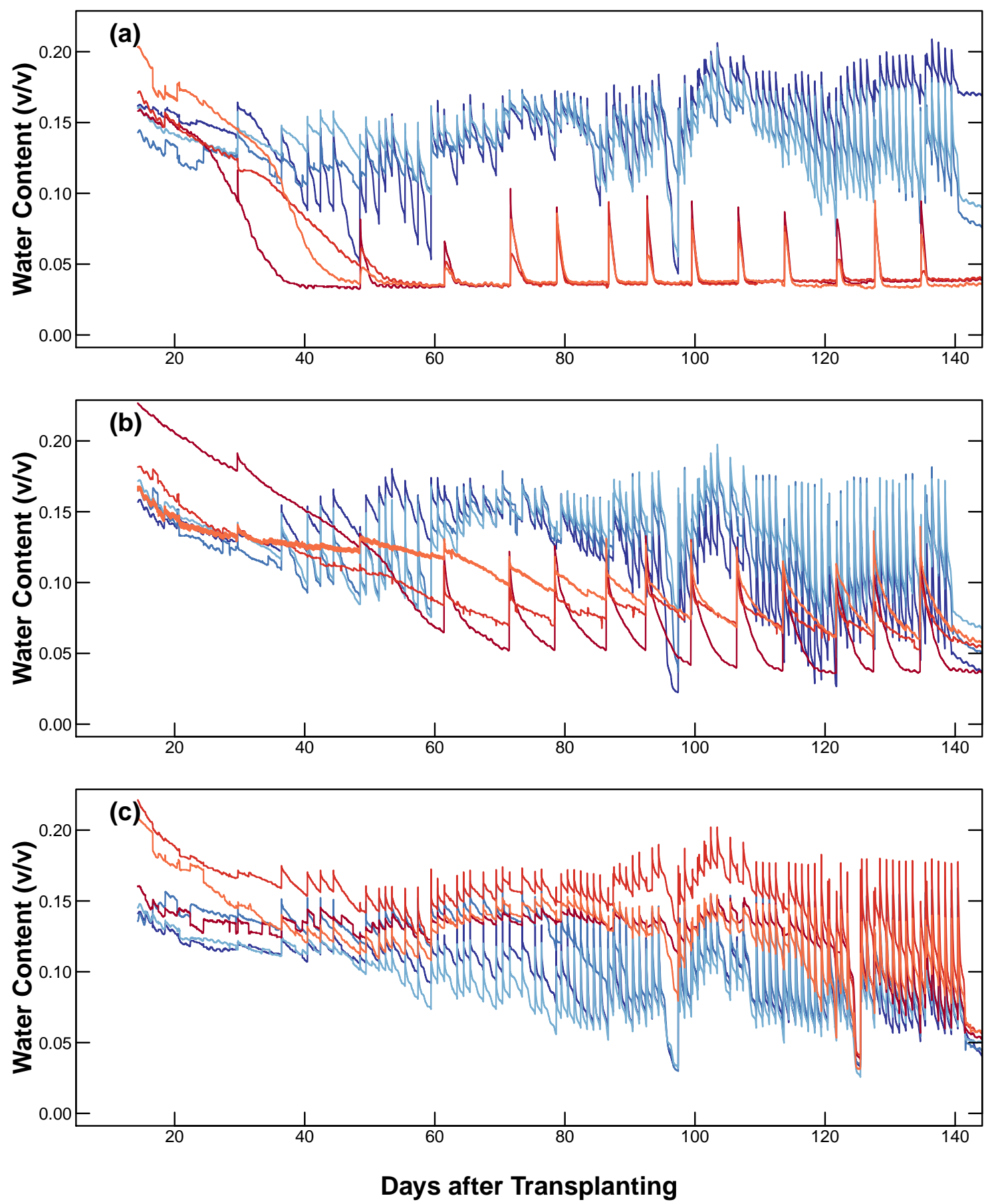

Figure 3. Long-term temporal changes in volumetric water content in different compartments of treatment $\mathbf{D}$ (a), $\mathbf{C 1}$ (b) and C2 (c). 


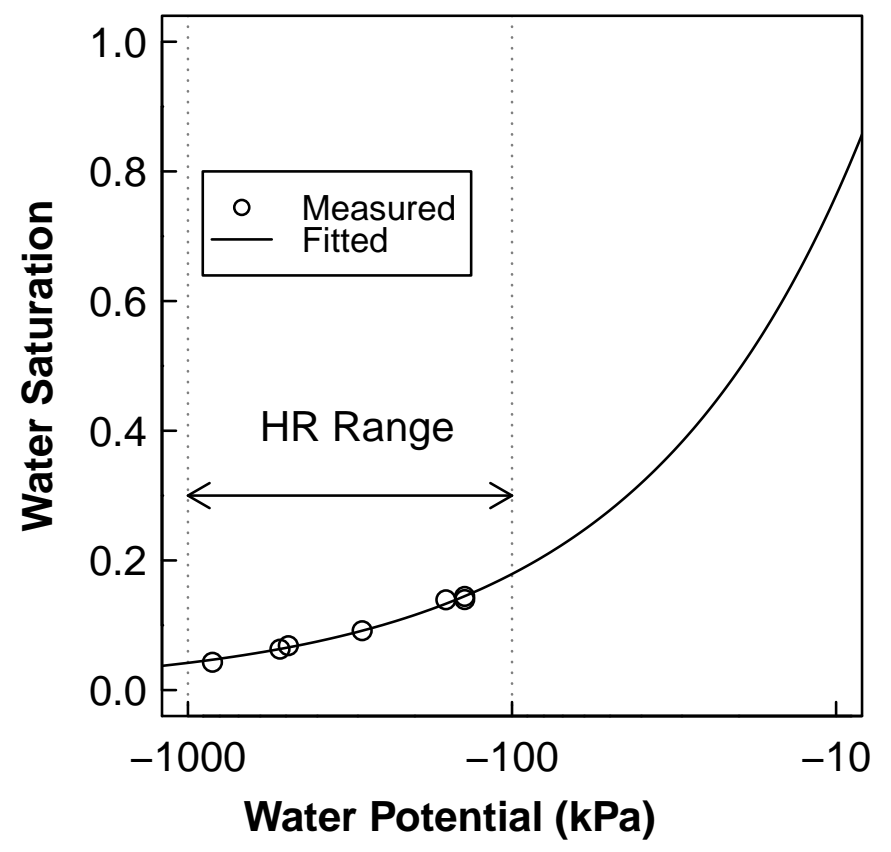

Figure 4. Water retention as a function of water potential derived from independent soil characterization. The relationship between water saturation and water potential is fitted with Brooks Corey's model using a solid line. 

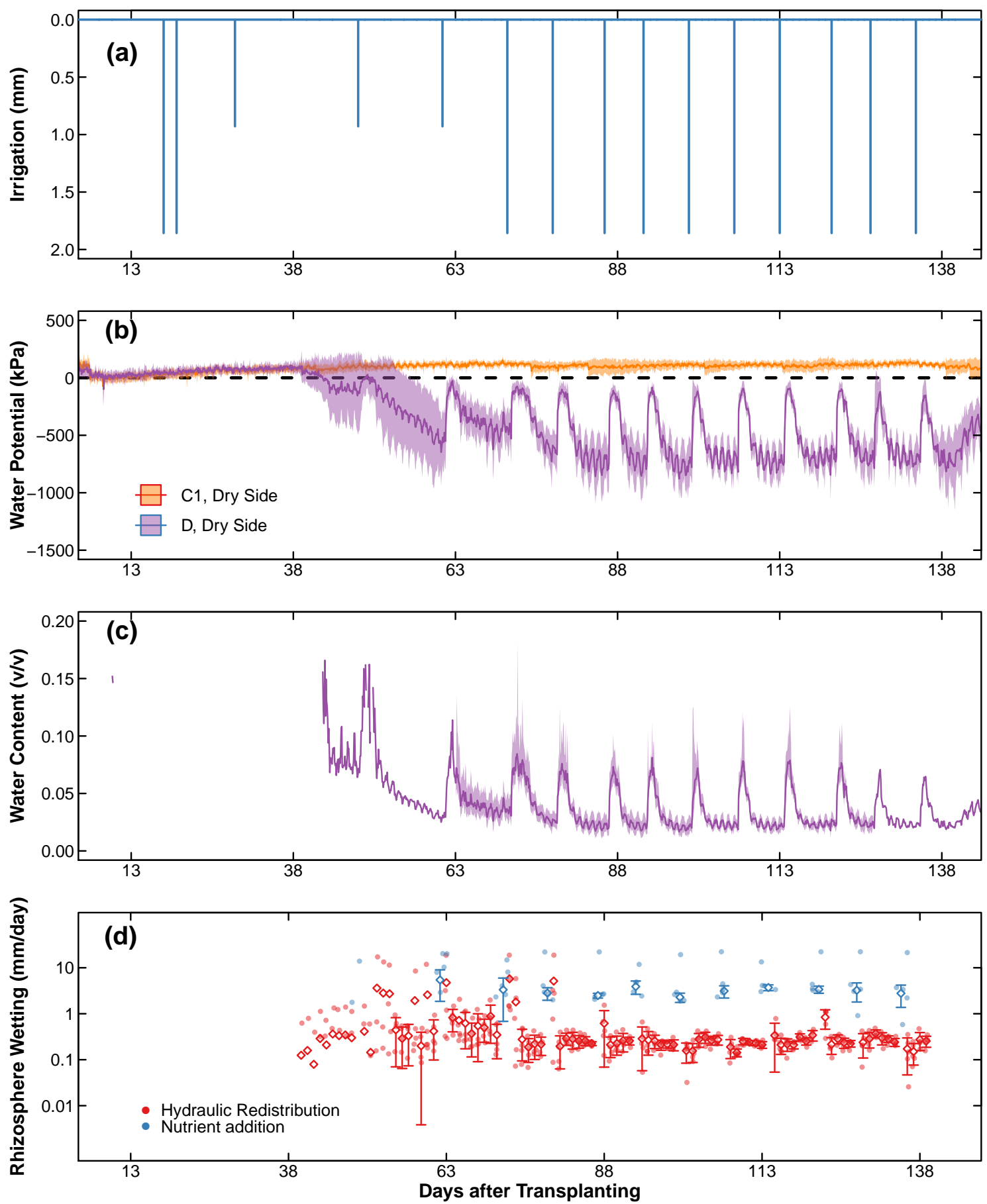

Figure 5. Wetting schemes (a) and temporal changes in water potential (b) in the "Dry" compartment of treatment D and C1; temporal changes in water content (c) and rhizosphere wetting (d) converted using water retention curves from day 4 to 149 after transplantation. 


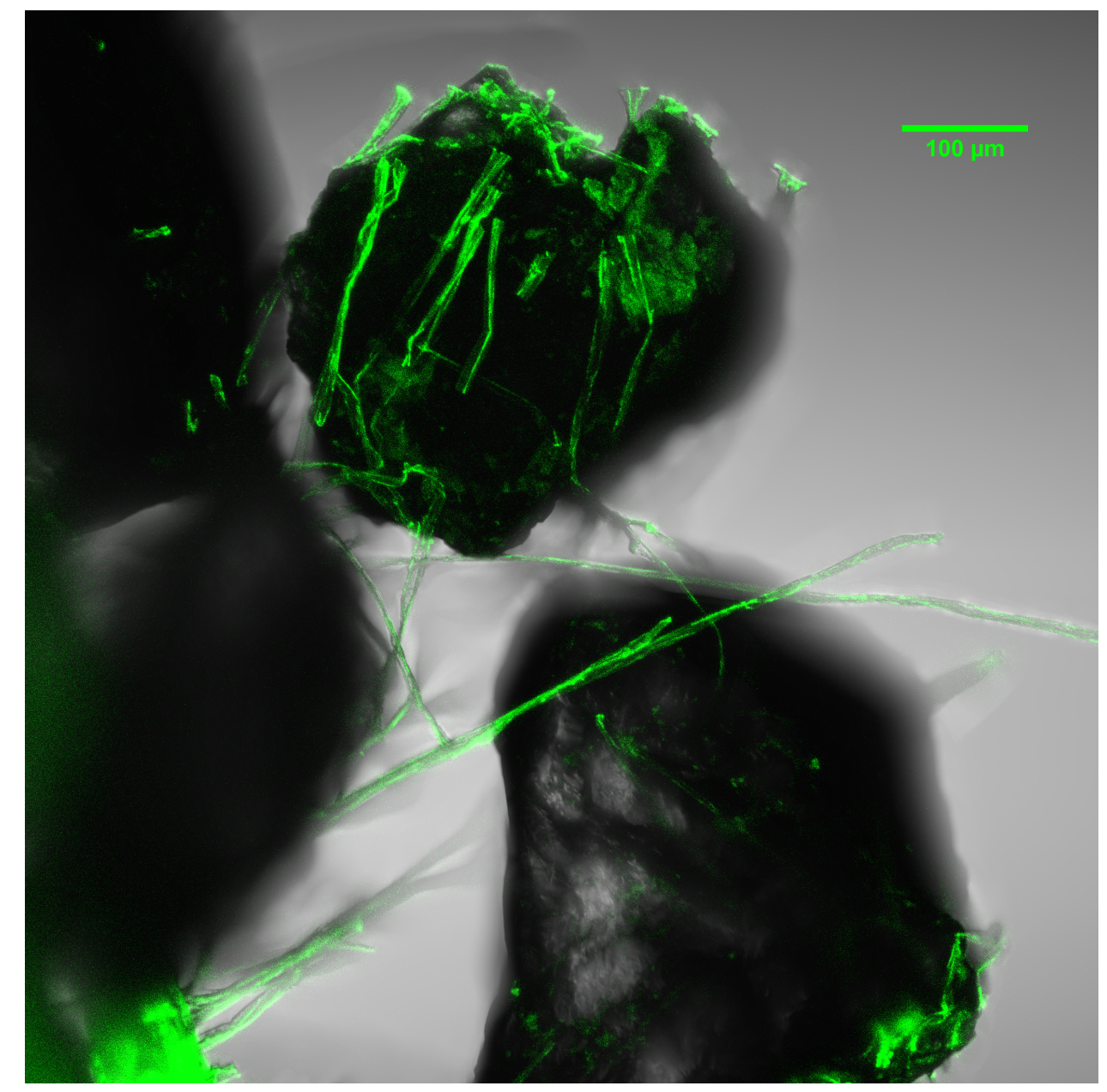

Figure 6. Confocal microscopic image of extensive fluorescent organic coating (depicted in green) on the surface of the sand particles inside the rhizosheath in the "Dry" compartment of treatment $\mathbf{D}$. 
Table 1. Brooks Corey's model parameters

\begin{tabular}{rrrrr}
\hline & $\theta_{r}(\mathrm{v} / \mathrm{v})$ & $\theta_{s}(\mathrm{v} / \mathrm{v})$ & $\lambda(-)$ & $\psi_{b}(-\mathrm{kPa})$ \\
\hline Measurement & 0.00 & 0.47 & -0.63 & 6.51 \\
\hline
\end{tabular}

\section{References}

Brooks, R. H. and Corey, A. T.: Hydraulic properties of porous media, no. 3 in Hydrology papers, Colorado State University, [Hydrology and Water Resources Program], Fort Collins, 1964.

Brooks, R. H. and Corey, A. T.: Properties of porous media affecting fluid flow, Journal of the irrigation and drainage division, 92, 61-90, 45 1966.

Games, P. A. and Howell, J. F.: Pairwise Multiple Comparison Procedures with Unequal N's and/or Variances: A Monte Carlo Study, Journal of Educational Statistics, 1, 113-125, https://doi.org/10.3102/10769986001002113, https://doi.org/10.3102/10769986001002113, 1976.

Kalra, Y. P.: Handbook of reference methods for plant analysis, CRC Press, Boca Raton, 1998.

Meinzer, F. C., Brooks, J. R., Bucci, S., Goldstein, G., Scholz, F. G., and Warren, J. M.: Converging patterns of uptake and hydraulic redistribution of soil water in contrasting woody vegetation types, Tree Physiology, 24, 919-928, https://doi.org/10.1093/treephys/24.8.919, 2004.

Welch, B. L.: The Generalization of 'Student's' Problem when Several Different Population Variances are Involved, Biometrika, 34, 28-35, https://doi.org/10.2307/2332510, http://www.jstor.org/stable/2332510, 1947. 